\title{
EVALUATION OF A NEW DIFFERENTIAL TEST FOR ENTEROCOCCI IN THE CLINICAL LABORATORY
}

\author{
Alexander von Graevenitz, John J. Redys and Eugene Cassidy \\ Clinical Microbiology Laboratories, Yale-New Haven Hospital, New Haven, Conn., USA, \\ and Connecticut State Department of Health, Laboratory Division, Hartford, Conn., USA
}

STREPTOCOCCI of the Lancefield group D comprise the enterococci (Sherman, 1937), as well as Streptococcus bovis and S. equinus. Among the former, the species $S$. faecalis (including var. liquefaciens and var. zymogenes) and S. faecium (including var. durans) are recognised at present (Deibel, 1964). All enterococci are characterised by growth $(a)$ at both $10^{\circ} \mathrm{C}$ and $45^{\circ} \mathrm{C},(b)$ in media with a $p \mathrm{H}$ of 9.6 and in media with a $\mathrm{NaCl}$ concentration of 6.5 per cent., and $(c)$ in $0 \cdot 1$ per cent. methylene blue milk with subsequent reduction. They also survive $60^{\circ} \mathrm{C}$ for $30 \mathrm{~min}$. and form ammonia from peptone (Sherman).

However, no single criterion is specific for enterococci. Growth is observed in S. bovis, in group-E streptococci (Breed, Murray and Smith, 1957) and in group-Q streptococci (Nowlan and Deibel, 1967) at $45^{\circ} \mathrm{C}$ and after $30 \mathrm{~min}$. of exposure to a temperature of $60^{\circ} \mathrm{C}$; all group-Q and some $S$. bovis strains (Raj and Colwell, 1966) grow in broth containing 6.5 per cent. NaCl. Group-B streptococci also grow in this medium as well as in Hajna's SF broth (Braunstein, Tucker and Gibson, 1969); and group-N streptococci grow in 0.1 per cent. methylene blue milk (Breed et al.). Conversely, occasional enterococcus strains may be atypical in one of these characteristics (Papavassiliou, 1962). Ideally, therefore, a spectrum of tests should be used for the identification of enterococci (Deibel), but this would probably overtax the resources of most clinical laboratories.

In the search for a single convenient test with sufficient clinical reliability, we decided to investigate a report (Booth, 1966) that a disk containing $5 \mu \mathrm{g}$ of cloxacillin (3-O-chlorophenyl-5-methyl-4-isoxazolyl-penicillin) did not inhibit the growth on Mueller-Hinton agar of any of 25 strains considered to be enterococci; 21 of them had been identified as group D and four were ungroupable, but all hydrolysed aesculin in 40 per cent. bile aesculin agar. In contrast, 17 strains of group-B, one of group-O, and two of ungroupable aesculin-hydrolysing streptococci gave inhibition zones around the disk.

The case for the use of penicillinase-resistant penicillin derivatives for the identification of enterococci is supported by earlier observations that enterococci are resistant in vitro to methicillin (dimethoxyphenyl-penicillin), oxacillin (methyl-phenyl-isoxazolyl-penicillin) and dicloxacillin \{3-(2,6-dichlorophenyl)-5-methyl-4-isoxazolyl-penicillin $\}$ (Klein and Finland, 1963; Barber and Waterworth, 1964; Hammerstrom et al., 1966). On the other hand, streptococci of the groups A, B, C and E, and viridans streptococci, were found to be sensitive to methicillin and oxacillin (Klein and Finland; Barber and Waterworth; Breitfellner, 1968) as well as to cloxacillin (Jones et al., 1967). The few enterococcus strains reported sensitive to these drugs are either not characterised serologically (Daikos, Kontomichalou and Paradelis, 1963; Fekety and Weiss, 1966), or have later been found resistant (Döll and Bredt, 1968; Duma et al., 1969; and our unpublished observations).

Received 24 Sept. 1969; accepted 11 Nov. 1969.

J. MED. MICROBIOL.-VOL. 3 (1970) 
The small number of streptococci tested against oxacillin and cloxacillin, and the lack of data on the inhibitory action of methicillin disks and on the susceptibility of individual species within the enterococcus group to penicillin derivatives, led us to investigate further the value of such a disk test.

\section{MATERIALS AND METHODS}

A total of 320 strains of grouped and ungroupable streptococci was examined (table I). Grouping was done by the precipitation technique (Lancefield, 1933) and group-D species

TABLE I

Results of methicillin and oxacillin disk tests

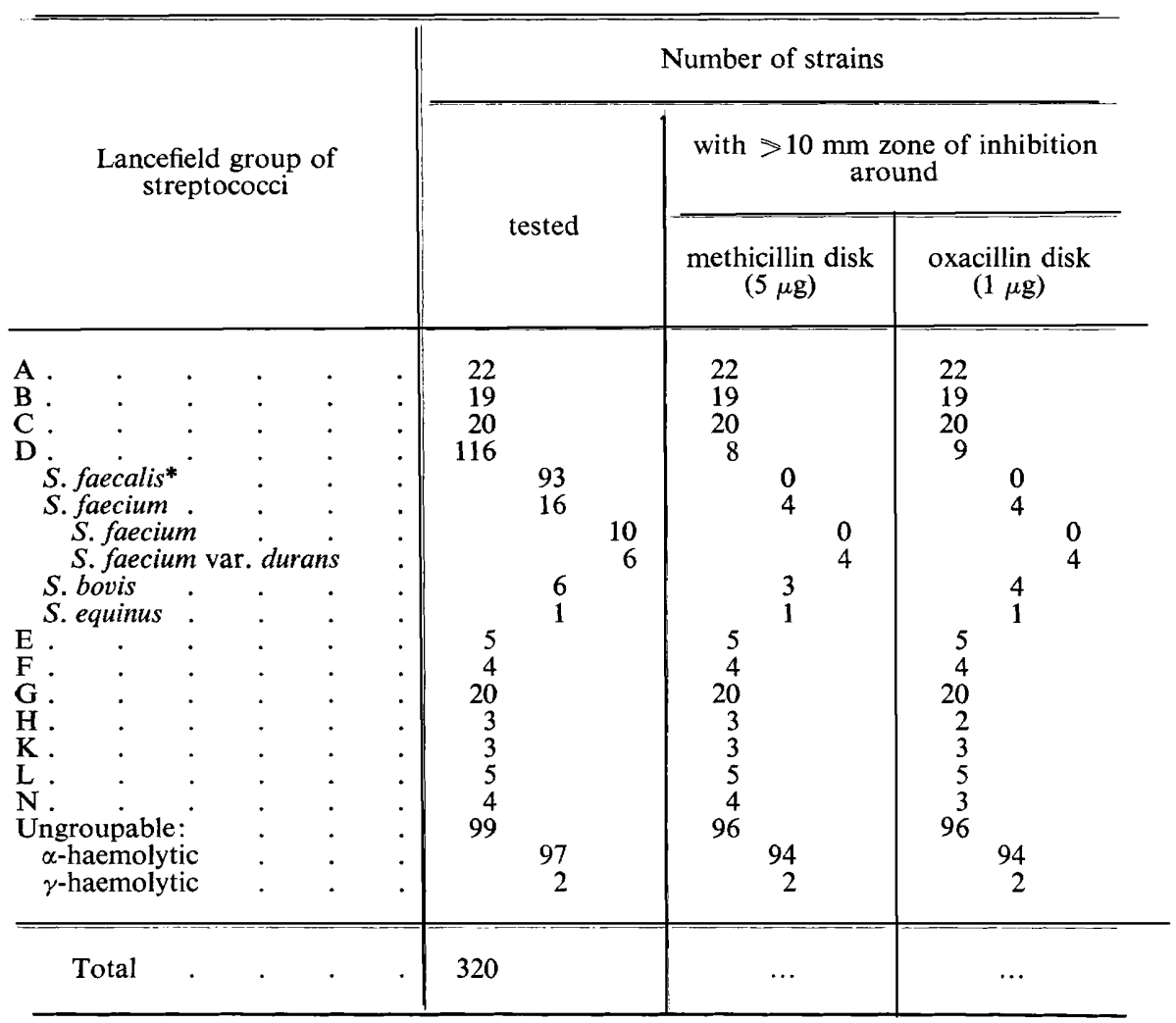

* Includes $S$. faecalis var. zymogenes and var. liquefaciens.

were identified biochemically (Deibel); 275 strains had been isolated in our laboratories from human material, and 45 were obtained from other laboratories.

For the disk test, the standard sensitivity method (Bauer et al., 1966) was used, with 6-mm diameter Sensi-Discs (Bio-Quest, Cockeysville, Md.) impregnated with $5 \mu \mathrm{g}$ of methicillin or $1 \mu \mathrm{g}$ of oxacillin, on Mueller-Hinton Agar (Bio-Quest) containing 4 per cent. sheep blood. Bacteria were considered resistant to methicillin if the diameter of the inhibition zone (including the disk) was less than $10 \mathrm{~mm}$ after incubation for $24 \mathrm{hr}$ at $37^{\circ} \mathrm{C}$ (Bauer et al.). Lacking a similar standard value for oxacillin, we assumed that at least the absence of a zone of inhibition indicated resistance. 


\section{RESULTS}

Whenever inhibition zones were observed, their diameter was $10 \mathrm{~mm}$ or more. All strains of groups A, B, C, E, F, G, K and L, two of group H, three of group $\mathrm{N}$, and the two ungroupable $\gamma$-haemolytic streptococci yielded zones around both disks (table I); 94 of the 97 ungroupable $\alpha$-haemolytic streptococci behaved similarly. One strain each of groups $\mathrm{H}$ and $\mathrm{N}$ was resistant to oxacillin only. Three ungroupable $\alpha$-haemolytic streptococci were resistant to both methicillin and oxacillin. When tested with a disk containing 10 units of penicillin $G$ these five strains showed zones with diameters larger than $20 \mathrm{~mm}$.

In the enterococcus group, all strains of $S$. faecalis and its varieties were resistant to both drugs (table I). The same was true for the S. faecium strains, but four of the six $S$. faecium var. durans strains did yield zones. Of the group-D strains other than enterococci, the $S$. equinus strain showed zones, whilst three of the six S. bovis strains were resistant to both drugs, and one was resistant to methicillin only.

\section{DISCUSSION}

Although a few ( 3 per cent.) of the ungroupable $\alpha$-haemolytic streptococci and some $S$. bovis strains showed an aberrant behaviour, the enterococci-and no other streptococci-were almost invariably inhibited by both methicillin and oxacillin. "False-negative" results were seen in S. bovis as well as in S. faecium var. durans. Group-Q streptococci-closely related to group D (Nowlan and Deibel, 1967)-were not available to us. We are unable to explain the three instances of differing results between the methicillin and oxacillin tests, particularly since cross-sensitivity between these drugs-and cloxacillin-has generally been observed in staphylococci, group-A streptococci and pneumococci (Sidell et al., 1963).

On the basis of our findings, a case can be made for the use of the methicillin disk test in the clinical laboratory. Firstly, S. faecalis predominates by far among the enterococci from pathological material, whilst $S$. faecium and the var. durans are very rare: table II compares the findings of two American and one German group in 1941, 1945 and 1968 respectively. In normal stools, on the other hand, both $S$. faecalis and $S$. faecium can be found (Deibel, 1964). Secondly, traditional tests lack specificity. A recent investigation showed that of 150 group-D streptococci, 100 per cent. hydrolysed aesculin on bile-aesculin medium (BAM), 90 per cent. tolerated heat, 85 per cent. tolerated salt, and 5 per cent. failed to tolerate both heat and salt. Conversely, of $150 \alpha$-haemolytic streptococci not groupable in A-O sera, 3 per cent. gave a positive BAM reaction, 17 per cent. were heat tolerant, 10 per cent. were salt tolerant, and 8 per cent. were tolerant to both heat and salt (Facklam and Moody, 1969). Another author found salt tolerance in all of 131 strains of $S$. faecium tested (not including var. durans), but only in 86 per cent. of 83 strains of $S$. faecalis (Papavassiliou, 1962). In a further study, $97 \cdot 8$ per cent. of 1792 enterococci and 4.9 per cent. of 2964 other streptococci grew at $45^{\circ} \mathrm{C}$ (Heeschen, Tölle and Zeidler, 1967). Finally, development of resistance to penicillinase-resistant penicillins among streptococci of groups other than D has not been so far described. 
Thus, the test seems both reasonably reliable and convenient, particularly since in many laboratories staphylococci and enterococci are routinely tested against the same array of antibiotics, which includes methicillin.

It should be emphasised that the results of our disk tests cannot for every case be translated directly into in-vivo sensitivity or resistance (Bauer et al., 1966). In this study, we were not concerned with MIC values or with the treatment of streptococcal infections, but rather with a diagnostic test for enterococci in the clinical laboratory.

TABLE II

Distribution of group-D streptococcal species in pathological material from human sources

\begin{tabular}{|c|c|c|c|c|c|c|c|}
\hline \multirow{3}{*}{ Reference } & \multirow{3}{*}{$\begin{array}{l}\text { Source of } \\
\text { cultures }\end{array}$} & \multicolumn{5}{|c|}{ Number of cultures of } & \multirow{3}{*}{$\begin{array}{c}\text { Total } \\
\text { number of } \\
\text { cultures }\end{array}$} \\
\hline & & \multicolumn{3}{|c|}{ Streptococcus faecalis } & \multirow{2}{*}{$\begin{array}{c}\text { S. faecium } \\
\text { var. } \\
\text { durans }\end{array}$} & \multirow{2}{*}{$\begin{array}{l}\text { unnamed } \\
\text { group-D } \\
\text { strepto- } \\
\text { cocci }\end{array}$} & \\
\hline & & total & $\begin{array}{l}\text { var. } \\
\text { lique- } \\
\text { faciens }\end{array}$ & $\begin{array}{l}\text { var. } \\
\text { zymo- } \\
\text { genes }\end{array}$ & & & \\
\hline Porch (1941) . & $\begin{array}{l}\text { genito- } \\
\text { urinary } \\
\text { tract }\end{array}$ & 73 & 3 & $\mathbf{0}$ & 0 & 0 & 73 \\
\hline $\begin{array}{l}\text { Brown and Schaub } \\
\text { (1945) }\end{array}$ & $\ldots$ & 339 & 15 & 6 & 1 & 46 & 386 \\
\hline $\begin{array}{l}\text { Döll and Bredt } \\
\text { (1968) }\end{array}$ & urine & 119 & 37 & 74 & 1 & 0 & 120 \\
\hline
\end{tabular}

$\ldots=$ Not stated.

\section{SUMMARY}

An identification method based on the failure of methicillin $(5 \mu \mathrm{g})$ and oxacillin $(1 \mu \mathrm{g})$ disks to inhibit enterococci on Mueller-Hinton Agar was evaluated. All strains tested of Streptococcus faecalis and its varieties and of S. faecium grew up to the edge of the disks; inhibition of $S$. faecium var. durans and of $S$. bovis was variable. In contrast, $S$. equinus and almost all streptococci not belonging to group-D streptococci showed inhibition zones of $10 \mathrm{~mm}$ or more.

The methicillin test seems suitable for use in the clinical laboratory in view of the scarcity of $S$. faecium var. durans, $S$. bovis and $S$. equinus in pathological material from man and of the margin of error of the traditional tests for enterococci.

We are indebted to the following for providing us with streptococcus strains of various groups: Dr Robert Deibel, University of Wisconsin, Madison, Wis.; Dr Werner Döll, Institut für Hygiene und Mikrobiologie der Universität Würzburg, Germany; Dr Richard Duma, Medical College of Virginia, Richmond, Va.; Dr Paul Hartman, Iowa State 
University, Ames, Iowa; Dr Maclyn McCarty, The Rockefeller University, New York, N.Y.; Dr Max Moody, National Communicable Disease Center, Atlanta, Ga.; Dr Harkisan Raj, California State College, Long Beach, Calif.; Dr Meyer Wolin, University of Illinois, Urbana, Ill.

From the American Type Culture Collection, Rockville, Md., we received strains no. 19434 (S. faecium), 6056 and 19432 (S. faecium var. durans), 9809 (S. bovis), and 9812 (S. equinus).

\section{REFERENCES}

Barber, Mary, AND Waterworth, 1964. Br. Med.J., 2, 344. PAMEla M.

Bauer, A. W., Kirby, W. M. M., 1966. Amer. J. Clin. Path., 45, 493. SHERRIS, J. C., AND TURCK, M.

BOOTH, E. V.

1966. Canad. J. Med. Technol., 28, 196.

Braunstein, H., Tucker, E. B., ANd 1969. Amer. J. Clin. Path., 51, 207. GiBson, B. C.

Breed, R. S., Murray, E. G. D., AND 1957. Bergey's Manual of determinative bacSMITH, N. R.

BreItFellner, G. . . . . . . . 1968. Chemotherapia, 13, 212.

Brown, J. H., and Schaub, I. G. . . . 1945. Amer. J. Med. Sci., 209, 388.

Daikos, G. K., Kontomichalou, P., 1963. Dt. med. Wschr., 88, 1678. and Paradelis, A.

DeIBel, R. H. . . . . . . . . 1964. Bact. Rev., 28, 330.

Döll, W., ANd Bredt, W. . . . . 1968. Zentbl. Bakt. ParasitKde, Abt. I, Orig., 209, 18.

Duma, R. J., Weinberg, A. N., Medrek, 1969. Medicine, Baltimore, 48, 87.

T. F., AND KUNZ, L. J.

Facklam, R. R., AND Moody, M. D. . 1969. Bact. Proc., p. 72.

FeKetY, F. R., JR, AND WeIss, P.. . . . 1966. In Antimicrobial agents and chemotherapy, 1965, ed. by Gladys L. Hobby, Ann Arbor, p. 156.

Hammerstrom, C.F., Cox, F., MCHenry, 1966. Ibid., p. 69. M. C., AND QUINN, E. L.

Heeschen, W., Tölle, H., ANd Zeidler, H.

Jones, A., Higgs, T. M., Neave, F. K., 1967. J. Dairy Res., 34, 249. AND SMITH, A.

KLEIN, J. O., AND FINLAND, M.

LANCEFIELD, REBECCA C. . . . . . .

Nowlan, S. S., and Deibel, R. H. . .

Papavassiliou, J. · . . . . . . . . . 1962. Appl. Microbiol., 10, 65.

PORCH, M. L. . . . . . . . . 1941. J. Bact., 41, 485.

RaJ, H., AND Colwell, R. R. . . . . 1966. Canad. J. Microbiol., 12, 353.

SHERmAN, J. M. . . . . . . . 1937. Bact. Rev., 1, 3.

Sidell, S., Burdick, R. E., Brodie, J., 1963. Archs Intern. Med., 112, 21. 